\title{
Eye complications of diabetes
}

\author{
Giuseppe Querques ${ }^{1}$
}

Received: 4 June 2019 / Accepted: 5 June 2019 / Published online: 15 June 2019

(c) Springer-Verlag Italia S.r.l., part of Springer Nature 2019

As we observe a dramatic increase in the number of persons affected by diabetes worldwide, diabetes-associated eye complications are rapidly emerging as a global health issue that may threaten patients' visual acuity and visual function. Even though treatment of diabetic retinopathy can reduce the risk of visual loss by $60 \%$ [1], diabetic retinopathy still remains the leading cause of blindness among working-age adults.

There are some difficulties that medical doctors and ophthalmologists face regarding diabetic retinopathy. First, communication between ophthalmologists and medical physicians is challenging, as well as indispensable, assuming that glucose and blood pressure control, and management of dyslipidemia plays important roles in preventing the development of or retarding the progression of diabetic retinopathy.

Furthermore, an early detection of diabetic retinopathy is essential for a proper management of this disorder and to reduce its associated complications (e.g., retinal detachment). Notably, diabetic retinopathy meets all the criteria for screening: (1) the condition is an important public healthcare problem; (2) the screening test (retinal photography) is simple, safe, validated, and acceptable; and (3) effective treatments are available for patients. In addition, newer techniques like stereoscopic imaging have significantly increased interest in telemedicine and further highlighted importance of education of general ophthalmologists and the medical physicians.

Finally, recent advancements in retinal imaging have provided further insight into the pathogenesis of diabetes and diabetic retinopathy. Recent studies employing optical coherence tomography (OCT) identified neuroretinal abnormalities in subjects affected by diabetes and without diabetic retinopathy [2]. OCT angiography (OCTA) analysis demonstrated that subtle vascular alterations may precede signs of diabetic retinopathy and neuroretinopathy [3, 4]. Continuous improvements in retinal imaging have resulted in research in

Giuseppe Querques

giuseppe.querques@hotmail.it

1 Ophthalmology Department, University Vita-Salute, IRCCS Ospedale San Raffaele Hospital, Via Olgettina 60, Milan, Italy diabetes-associated ocular complications being a flourishing field in the clinical research.

All these aspects emphasize the importance of laboratory and clinical studies on diabetes-associated complications. These studies are also aimed at enhancing communication between ophthalmologists, diabetologists, nephrologists, and all those who take care of diabetic patients. Many contributions about eye and diabetes were published in Acta Diabetologica in the last years. However, given its relevance, we open a new topical collection dedicated to the diabetesassociated complications, in order to improve communications among clinicians and researchers interested in diabetes.

\section{Compliance with ethical standards}

Conflict of interest The author declares that he/she has no conflict of interest.

Ethical approval This article does not contain any studies with human participants performed by the author.

\section{References}

1. American Diabetes Association AD (2010) Standards of medical care in diabetes-2010. Diabetes Care 33(Suppl 1):S11-61. https ://doi.org/10.2337/dc10-S011

2. Picconi F, Parravano M, Ylli D et al (2017) Retinal neurodegeneration in patients with type 1 diabetes mellitus: the role of glycemic variability. Acta Diabetol 54:489-497. https://doi.org/10.1007/ s00592-017-0971-4

3. Carnevali A, Sacconi R, Corbelli E et al (2017) Optical coherence tomography angiography analysis of retinal vascular plexuses and choriocapillaris in patients with type 1 diabetes without diabetic retinopathy. Acta Diabetol 54:695-702. https://doi.org/10.1007/ s00592-017-0996-8

4. Cao D, Yang D, Huang Z et al (2018) Optical coherence tomography angiography discerns preclinical diabetic retinopathy in eyes of patients with type 2 diabetes without clinical diabetic retinopathy. Acta Diabetol 55:469-477. https://doi.org/10.1007/s0059 2-018-1115-1

Publisher's Note Springer Nature remains neutral with regard to jurisdictional claims in published maps and institutional affiliations. 